\title{
Caffeine and Health and Cognition in the Elderly
}

\author{
Andrew P. Smith \\ School of Psychology, Cardiff University, 63 Park Place, Cardiff, CF10 3AS, UK \\ Received September 24, 2020; Accepted November 22, 2020 \\ Communicated By: Prof. Orlando Petrini \& Prof. Jonathon Reay
}

The behavioral effects of caffeine are well documented, and research suggests that caffeine may help to prevent and manage cognitive changes as a person gets older. The present article describes a secondary analysis of epidemiological data from a sample of 3659 volunteers (average age: 70 years; range 61-98 years). Information about regular caffeine consumption was collected. Demographic variables were used as covariates in the analyses. The outcomes were ratings of general health, anxiety and depression scores (from the Hospital Anxiety and Depression Scale), and the frequency of cognitive failures. The results showed that higher caffeine consumption was associated with better reported health, lower anxiety and depression scores, and fewer cognitive failures. Caffeine from coffee was responsible for these associations. These findings confirm that caffeine may help prevent cognitive deficits and manage the health and cognition of the elderly. Longitudinal studies, preferably with interventions, are needed to provide evidence of causal mechanisms.

Keywords: Anxiety, Caffeine, Cognition, Depression, Health, The Elderly

Corresponding Author: Prof. Andrew P. Smith, School of Psychology, Cardiff University, 63 Park Place, Cardiff, CF10 3AS, UK; E-mail: smithap@cardiff.ac.uk

\section{INTRODUCTION}

\section{Caffeine and Its Mechanism of Action}

The principal sources of caffeine, a methylxantine, are coffee, tea and energy drinks. Small amounts are found in cocoa and chocolate, and caffeine is added to soft drinks and medicines. Individual daily consumption has been estimated to be 200-450 mg (Gilbert, 1984) and intra-individual consumption is consistent over time, as is the considerable inter-individual variation. Peak plasma concentration is typically reached in 30-60 min after ingestion (Rall, 1980). The half-life of caffeine varies between 3-7 h with an average of about $5 \mathrm{~h}$.

The most plausible mechanism of caffeine, at doses achieved during normal usage, is blockade of adenosine receptors (Fredholm, 1995), which produces stimulant effects (Franchetti et al., 1994). In addition to central nervous system effects, caffeine also affects the autonomic nervous system. Studies have shown increased electromyographic activity (James, 1990), increased skin conductance (e.g., Smith et al., 1993) and raised skin temperature (e.g., Koot and Deurenberg,1995). Caffeine increases blood pressure (e.g., Smits et al., 1993), an effect largely due to increased vascular resistance (e.g. Biaggioni et al., 1991). Caffeine also has diuretic effects (Fredholm, 1984), and stimulates gastric secretion (Cohen and Booth, 1975). It has also been shown to increase basal metabolic rate (e.g. Poehlman et al., 1989), and change neuroendocrine function. Research has shown increases in adrenaline, noradrenaline (Lane et al., 1990) and cortisol (Lovallo et al., 1989) after caffeine consumption.

Several mechanisms of action of caffeine at the cellular level have been proposed (see Fredholm et al., 1999; Nehlig et al., 1992). The most plausible mechanism in humans is adenosine receptor antagonism. Other research has examined the effects of caffeine on neurotransmitters and some of the behavioral effects of caffeine could reflect changes in endogenous catecholamines. This can be related to adenosine, which inhibits the release of various neurotransmitters through presynaptic receptors. Therefore, adenosine antagonists, such as caffeine, can be expected to increase release of certain neurotransmitters. Caffeine increases the rates of synthesis and turnover of noradrenaline (see Nehlig et al., 1999, for a review). There is supporting empirical evidence for this view; Smith et al. (2003) found that caffeine reversed the behavioral impairments seen following administration of clonidine, a drug which at low doses acts pre-synaptically, binding to autoreceptors that reduce the turnover of central noradrenaline.

Caffeine can also increase behaviours related to dopamine. Garrett and Griffiths (1997) suggested that such effects of caffeine reflect indirect action on dopamine receptors that is secondary to the antagonism of adenosine receptors. Roache and Griffiths (1987) found that diazepam and caffeine generally produced opposing and/or mutually antagonistic effects. Increased cerebral 
concentrations of serotonin and its precursor tryptophan have been found following caffeine, although these studies have used doses greater than those typically consumed by humans. Caffeine can also reverse some of the behavioral impairments induced by a scopolamine challenge (Riedel et al., 1995), which suggests that it influences the cholinergic system. Overall, caffeine has many varied effects on neurotransmitters which largely reflect changes in adenosine and the subsequent effects at the pre-synaptic receptors.

Caffeine has a unique mechanism of action among all central stimulant drugs. For example, the mechanism of caffeine is different from that of amphetamine or cocaine (see Fredholm et al., 1999, and Nehlig, 1999, for reviews). It does not increase the release of dopamine nor lead to increased activation of D1 dopaminergic neurotransmission in the nucleus accumbens. Caffeine can also change local levels of cerebral energy metabolism. These local increases of cerebral glucose utilisation occur in areas which underlie the positive behavioral effects of caffeine. Caffeine also reduces cerebral blood flow in areas where energy metabolism is simultaneously increased (Nehlig, 1994). Caffeine resets the coupling between metabolism and cerebral blood flow, with behavioral effects often reflecting a restoration of function rather than stimulation above normal levels. A variation of the CYP1A2 gene $(-163 \mathrm{~A}>\mathrm{C})$ influences the rate of caffeine metabolism (see Doepker et al., 2016), which may underlie the variation of CNS effects and other physiological changes induced by caffeine.

\section{Behavioral Effects of Caffeine}

The effects of caffeine on behaviour have been frequently discussed. Reviews by Doepker et al. (2016), Glade (2010), Lieberman (1992), and Smith $(2002,2005 a, 2011,2014,2018)$ suggest that the behavioral effects of caffeine are largely positive except in sensitive individuals and after very large doses. Glade (2010) concludes that moderate amounts of caffeine lead to enhanced cognitive performance; better motor performance; increased wakefulness, alertness and feelings of energy; decreased mental fatigue; more accurate and faster reactions; increased concentration and focusing of attention; enhanced short term memory; and increased logical reasoning. Some effects of caffeine are often most beneficial when alertness is reduced, e.g. under sleep deprivation, when working at night, when the person has a cold, and after lunch (see Smith, 2011, for a review).

\section{Effects of Caffeine on Anxiety, Depression and Sleep}

Caffeinism is usually associated with daily intakes between 1000 and $1500 \mathrm{mg}$. It refers to symptoms that are virtually indistinguishable from severe chronic anxiety. However, there is little evidence of a correlation between caffeine intake and anxiety in non-clinical volunteers or psychiatric outpatients (Lara, 2010). In the case of depression, moderate caffeine intake has been associated with fewer symptoms and a reduced risk of suicide. Smith (2011) carried out secondary analyses of a large epidemiological database which showed that caffeine consumption was associated with reduced depression.
One of the negative effects associated with caffeine is impaired sleep. Research suggests that sleep disruption is apparent when higher doses $(>300 \mathrm{mg}$ ) of caffeine are consumed immediately before bedtime. Indeed, consumers often reduce their consumption later in the day to prevent sleep disturbance.

\section{Caffeine and Real-Life Performance}

Smith (2005b) investigated associations between habitual caffeine consumption and performance and safety at work. Those who consumed more caffeine reported greater increases in alertness and a smaller slowing of reaction time over the working day. Higher caffeine consumers had about half the risk of frequent/ very frequent cognitive failures and a reduced risk for accidents at work. These effects have also been found in a non-working sample (Smith, 2009).

There has been considerable research on caffeine and sustained military operations. Lieberman et al. (2002) concluded that "When cognitive performance is critical and must be maintained during exposure to severe stress, administration of caffeine may provide a significant advantage". A systematic review (Ker et al., 2010) examined the effects of caffeine on shift-workers and concluded that "Based on the current evidence, there is no reason for healthy individuals who already use caffeine within recommended levels to improve their alertness to stop doing so."

\section{Caffeine and Driving}

Smith (2014) conducted a study investigating associations between caffeine consumption and road traffic accidents in a representative community sample. The results showed that consumption of caffeine nearly halved the risk of being involved in a road accident.

\section{Caffeine and Cognitive Function in the Elderly}

A systematic review and meta-analysis (Santos et al., 2010) considered nine cohort and two case control studies investigating the relationship between caffeine consumption and dementia/ cognitive impairment in the elderly. The meta-analysis showed a trend towards a protective effect of caffeine. Kromhout et al. (2020) examined associations between caffeine consumption, behavioral problems and mental health in the elderly in care homes. Of the 206 participants, 70\% showed behavioral symptoms. An increase in caffeine consumption was associated with a decrease in the presence of behavioral symptoms such as affect and agitation. High and low caffeine consumption groups also differed on the presence of disinhibition and depression.

\section{CAFFEINE AND THE HEALTH AND COGNITION OF THE ELDERLY}

The present study examined caffeine, cognition and mental health in a free-living sample of elderly adults. Smith (2005) and Smith (2009) conducted secondary epidemiological analyses on data from the Bristol Stress and Health at Work survey (Smith et al., 2000) and the Cardiff Health Survey (Wadsworth et al., 2003), and showed that higher consumption of caffeine was associated with 
fewer cognitive failures and better safety (fewer minor injuries and accidents). The present study continued these analyses but focused on the group aged over 60 years. In addition to cognitive functioning, the analyses also examined general health, anxiety and depression.

\section{Participants and Methods}

This study is based on a secondary analysis of the database used by Smith $(2005,2009)$. These studies were approved by the local research ethical committees and carried out with the informed consent of the volunteers. This database contained information on level of caffeine consumption, cognitive failures, general health, anxiety and depression. It also contained information about possible confounders that need to be controlled in such analyses (e.g. demographics - see Wadsworth et al., 2003).

\section{Participants}

3659 participants, aged over 60 years, were included in the analysis.

\section{Methods}

Participants reported their daily consumption of caffeinated beverages and these were converted to caffeine content [mg] using the method described by Brice and Smith (2002).

General Health was measured using a single question: "Over the past 12 months, how would you say your health in general has been?" The rating scale consisted of "Very good", "Good", "Fair", "Bad" and "Very Bad".

Anxiety and Depression were measured using the Hospital Anxiety and Depression Scale (HADS; Zigmond and Snaith, 1983).

Cognitive Failures involved a single question covering failures of memory, attention and action: "How frequently do you find that you have problems of memory (e.g. forgetting where you put things), attention (e.g. failures of concentration) or action (doing the wrong thing)?" [responses were on a 5-point rating scale from "not at all" to "very frequently"].

\section{Statistical Analysis}

Linear regressions were carried out to determine whether caffeine consumption predicted cognitive failures, general health, anxiety and depression. Demographic variables were entered in the first step of the regression (model 1) followed by caffeine consumption (model 2). Interactions were not included in the models as there was no a priori reason for predicting them. The analyses were carried out using IBM SPSS version 25.

\section{RESULTS}

The demographic characteristics of the participants, and their caffeine consumption levels, are given in Table 1.

Data on cognitive failures were only available from 1347 participants. Table 2 shows the cognitive failures regression.

The frequency of cognitive failures increased with age and decreased with greater caffeine consumption. The results of the regression using general health in the last 12 months as the dependent variable is shown in Table 3.
TABLE 1 | Demographic characteristics of the sample and levels of caffeine consumption.

\begin{tabular}{ll}
\hline Age & Median = 70 years \\
& Range: $61-98$ years \\
Gender & $47.9 \%$ Male \\
Marital Status & Married: $63.5 \%$ \\
& Single: $6.1 \%$ \\
& Divorced: $5.8 \%$ \\
& Widowed: $23.1 \%$ \\
& 85\% not working \\
Employment status & $98 \%$ white \\
Ethnicity & None: $40.5 \%$ \\
Highest Educational Qualification & GCSE: $12.7 \%$ \\
& Advanced Level: $5.3 \%$ \\
& National Diploma: $9.3 \%$ \\
& Degree: $2.4 \%$ \\
& Higher Degree: $8.3 \%$ \\
Overall daily caffeine consumption & Mean = 249 mg (95\% Cl: 244, 253) \\
Daily caffeine from coffee & Mean = 96 mg (95\% Cl: 92, 100) \\
Daily caffeine from tea & Mean = 153 mg (95\% Cl: 149, 156) \\
\hline
\end{tabular}

TABLE 2 | Regression examining whether caffeine consumption predicts cognitive failures (high scores $=$ more frequent cognitive failures).

\begin{tabular}{llccccccc}
\hline Model & & \multicolumn{2}{c}{$\begin{array}{c}\text { Unstandardized } \\
\text { Coefficients }\end{array}$} & & & \multicolumn{3}{c}{$\begin{array}{c}\text { Standardized } \\
\text { Coefficients }\end{array}$} \\
\cline { 3 - 4 } \cline { 6 - 8 } & & $\mathbf{B}$ & Std. Error & & Beta & $\mathbf{t}$ & $\mathbf{P}$ \\
\hline 1 & (Constant) & .729 & .285 & & & 2.555 & .011 \\
& Age & .012 & .004 & & .082 & 2.902 & .004 \\
& (Constant) & .881 & .295 & & & 2.985 & .003 \\
& Age & .011 & .004 & & .077 & 2.708 & .007 \\
& Caffeine & .000 & .000 & & -.054 & -1.982 & .048 \\
\hline
\end{tabular}

TABLE 3 | Regression examining whether caffeine consumption predicts general health over the last 12 months (low scores = better general health).

\begin{tabular}{|c|c|c|c|c|c|c|}
\hline \multirow[t]{2}{*}{ Model } & & \multicolumn{2}{|c|}{$\begin{array}{l}\text { Unstandardized } \\
\text { Coefficients }\end{array}$} & \multicolumn{3}{|c|}{$\begin{array}{c}\text { Standardized } \\
\text { Coefficients }\end{array}$} \\
\hline & & B & Std. Error & Beta & $\mathbf{t}$ & $\mathbf{P}$ \\
\hline \multirow[t]{3}{*}{1} & (Constant) & .286 & .158 & & 1.805 & .071 \\
\hline & Marital status & .024 & .010 & .046 & 2.564 & .010 \\
\hline & Age & .016 & .002 & .125 & 7.238 & .000 \\
\hline \multirow[t]{4}{*}{2} & (Constant) & .415 & .164 & & 2.536 & .011 \\
\hline & Marital status & .023 & .010 & .044 & 2.450 & .014 \\
\hline & Age & .016 & .002 & .120 & 6.929 & .000 \\
\hline & Caffeine & .000 & .000 & -.051 & -3.049 & .002 \\
\hline
\end{tabular}

Health was worse in those who were widowed and also declined with age. Higher caffeine consumption was associated with better subjectively perceived health. The results of a regression using anxiety over the last six months as the dependent variable are shown in Table 4.

Anxiety was higher in females, those who were widowed or divorced, and the younger participants. Higher caffeine consumption was associated with lower anxiety scores.

Finally, a regression examined whether caffeine consumption predicted depression; the results are shown in Table 5. 
TABLE 4 | Regression examining whether caffeine consumption predicts anxiety over the last 6 months (high scores = greater anxiety).

\begin{tabular}{|c|c|c|c|c|c|c|}
\hline \multirow[t]{2}{*}{ Model } & & \multicolumn{2}{|c|}{$\begin{array}{l}\text { Unstandardized } \\
\text { Coefficients }\end{array}$} & \multicolumn{3}{|c|}{$\begin{array}{l}\text { Standardized } \\
\text { Coefficients }\end{array}$} \\
\hline & & B & Std. Error & Beta & $\mathbf{t}$ & $\mathbf{P}$ \\
\hline \multirow[t]{4}{*}{1} & (Constant) & 7.364 & .740 & & 9.954 & .000 \\
\hline & Marital status & .119 & .044 & .051 & 2.722 & .007 \\
\hline & Sex & 1.396 & .144 & .174 & 9.713 & .000 \\
\hline & Age & -.041 & .010 & -.071 & -3.944 & .000 \\
\hline \multirow[t]{5}{*}{2} & (Constant) & 7.805 & .762 & & 10.246 & .000 \\
\hline & Marital status & .115 & .044 & .049 & 2.626 & .009 \\
\hline & Sex & 1.388 & .144 & .173 & 9.665 & .000 \\
\hline & Age & -.043 & .011 & -.074 & -4.115 & .000 \\
\hline & Caffeine & -.001 & .000 & -.042 & -2.402 & .016 \\
\hline
\end{tabular}

TABLE 5 | Regression examining whether caffeine consumption predicts depression over the last 6 months (high scores = greater depression).

\begin{tabular}{|c|c|c|c|c|c|c|}
\hline \multirow[t]{2}{*}{ Model } & & \multicolumn{2}{|c|}{$\begin{array}{l}\text { Unstandardized } \\
\text { Coefficients }\end{array}$} & \multicolumn{3}{|c|}{$\begin{array}{l}\text { Standardized } \\
\text { Coefficients }\end{array}$} \\
\hline & & B & Std. Error & Beta & $\mathbf{t}$ & $\mathbf{P}$ \\
\hline \multirow[t]{3}{*}{1} & (Constant) & -.400 & .623 & & -.642 & .521 \\
\hline & Marital status & .157 & .037 & .079 & 4.260 & .000 \\
\hline & Age & .063 & .009 & .127 & 7.116 & .000 \\
\hline \multirow[t]{4}{*}{2} & (Constant) & .044 & .642 & & .068 & .946 \\
\hline & Marital status & .153 & .037 & .077 & 4.172 & .000 \\
\hline & Age & .061 & .009 & .123 & 6.870 & .000 \\
\hline & Caffeine & -.001 & .000 & -.048 & -2.808 & .005 \\
\hline
\end{tabular}

TABLE 6. | Regression examining whether caffeine consumption predicts cognitive failures controlling for anxiety, depression and general health (high scores = more frequent cognitive failures).

\begin{tabular}{|c|c|c|c|c|c|c|}
\hline \multirow[t]{2}{*}{ Model } & & \multicolumn{2}{|c|}{$\begin{array}{l}\text { Unstandardized } \\
\text { Coefficients }\end{array}$} & \multicolumn{3}{|c|}{$\begin{array}{c}\text { Standardized } \\
\text { Coefficients }\end{array}$} \\
\hline & & B & Std. Error & Beta & $\mathbf{t}$ & $\mathbf{P}$ \\
\hline \multirow[t]{3}{*}{1} & (Constant) & .639 & .303 & & 2.109 & .035 \\
\hline & Marital status & .043 & .018 & .071 & 2.353 & .019 \\
\hline & Age & .013 & .004 & .087 & 2.951 & .003 \\
\hline \multirow[t]{6}{*}{2} & (Constant) & .403 & .306 & & 1.316 & .189 \\
\hline & Age & .012 & .004 & .082 & 2.838 & .005 \\
\hline & Caffeine & .000 & .000 & -.054 & -1.977 & .048 \\
\hline & Depression & .043 & .011 & .137 & 3.731 & .000 \\
\hline & Anxiety & .058 & .009 & .226 & 6.429 & .000 \\
\hline & $\begin{array}{l}\text { General health } \\
\text { over last } \\
12 \text { months }\end{array}$ & -.024 & .034 & -.022 & -.719 & .472 \\
\hline
\end{tabular}

Depression scores were higher in the older participants, and in those who were widowed or divorced. Also, here higher caffeine consumption was associated with lower depression scores.

A regression was also carried out to determine whether the association between caffeine and cognitive failures reflected the caffeine-mental health association. The results are presented in Table 6, and they show that the effects of caffeine on cognitive failures do not reflect the caffeine-mental health association, even though mental health was a strong predictor of cognitive failures.
TABLE 7 | Regressions examining effects of caffeine from coffee and tea on the outcomes.

\begin{tabular}{|c|c|c|c|c|c|}
\hline & \multicolumn{2}{|c|}{$\begin{array}{l}\text { Unstandardized } \\
\text { Coefficients }\end{array}$} & \multicolumn{3}{|c|}{$\begin{array}{l}\text { Standardized } \\
\text { Coefficients }\end{array}$} \\
\hline & B & Std. Error & Beta & $\mathbf{t}$ & $\mathbf{P}$ \\
\hline \multicolumn{6}{|l|}{ Cognitive Failures } \\
\hline Caffeine from Coffee & .000 & .000 & -.061 & -2.116 & .035 \\
\hline Caffeine from Tea & .000 & .000 & -.030 & -1.030 & .303 \\
\hline \multicolumn{6}{|l|}{ Depression } \\
\hline Caffeine from Coffee & -.002 & .000 & -.059 & -3.273 & .001 \\
\hline Caffeine from Tea & -.001 & .001 & -.019 & -1.092 & .275 \\
\hline \multicolumn{6}{|l|}{ Anxiety } \\
\hline Caffeine from Coffee & -.002 & .000 & -.059 & -3.273 & .001 \\
\hline Caffeine from Tea & -.001 & .001 & -.019 & -1.092 & .275 \\
\hline \multicolumn{6}{|l|}{ General Health } \\
\hline Caffeine from Coffee & .000 & .000 & -.059 & -3.403 & .001 \\
\hline Caffeine from Tea & .000 & .000 & -.023 & -1.362 & .173 \\
\hline
\end{tabular}

A final analysis examined whether the effects of caffeine were due to caffeine from coffee or tea (Table 7).

The results of the regressions showed that the higher caffeine amount from coffee was significantly associated with reduced cognitive failures, lower anxiety and depression, and better general health. Caffeine from tea was not significantly associated with any of the outcomes. Further analyses considered consumption of decaffeinated coffee and tea. Levels of consumption of these beverages were not significantly associated with the outcomes (all P-values $>0.05)$.

\section{DISCUSSION}

There is evidence in the literature that caffeine may help prevent or manage cognitive decline in the elderly. Much of this research has been conducted using samples where early signs of Alzheimer's disease or similar types of neurodegeneration are present. The present study extends these results to a younger sample living at home, and suggests that problems of memory, attention and action are reduced in people with greater caffeine consumption. Similar effects have been reported in samples of working age (Smith, 2005, 2009). The present results are consistent with a study by Jarvis (1993) that demonstrated significant dose-response relationships between caffeine intake and cognition, with the beneficial effects of caffeine being greater in the older participants.

There has been considerable research on caffeine and mental health, with a number of studies reporting low levels of depression in higher caffeine consumers (Wang et al., 2015; Grosso et al., 2016). The present study confirms these findings and extends them by demonstrating similar effects of caffeine in anxiety and general health. Further, research is now required to examine specific aspects of health to determine which show associations with caffeine.

The associations between total caffeine and the outcomes were due to caffeine from coffee. This may reflect the higher amounts of caffeine in coffee compared to tea. No significant associations 
were found with decaffeinated coffee and tea, which suggests that the associations were with caffeine and not the other constituents of the drinks.

The present study has a number of limitations. First, it was a cross-sectional study and future research should have a longitudinal design preferably with an intervention. Secondly, subjective reports were used, and future research should involve objective measurement of both the cognitive outcomes and the caffeine consumption. Further research with objective measurement of cognitive function is required to determine whether caffeine is associated with general benefit or only specific domains are improved. It is also possible that caffeine was restricted in some individuals because of existing health problems (e.g. cardiovascular issues), which could account for the reduced wellbeing in those who consumed less caffeine. Finally, some of the benefits of consuming caffeine could reflect the social situation rather than a direct pharmacological effect of caffeine. The results of this study add to the existing literature and the main conclusions about the effects of caffeine.

\section{ACKNOWLEDGMENTS}

This paper is dedicated to the memory of Keith Wesnes. When I first met Keith Wesnes in the early 1980's we were both doing research on the effects of changes of state on cognitive function. Keith was working on the effects of smoking and nicotine, and I was carrying out studies on the effects of noise, caffeine and meals. We had a shared interest in the development of cognitive testing and identified how it could be applied to other areas. Keith conducted substantial research in the effects of ageing, and the prevention and management of cognitive decline. I started to conduct field studies examining cognition and health in workers and in educational settings.

I have carried out very little research on ageing, but the study reported here is very relevant to an area Keith and I often discussed, namely the beneficial effects of caffeine. Keith carried out research on caffeine and demonstrated that positive effects may last up to $6 \mathrm{~h}$ (Wesnes et al., 2013).

\section{CONFLICT OF INTEREST DECLARATION}

The author declares no conflict of interest.

\section{REFERENCES}

Biaggioni, I., Saul, S., Puckett, A. and Arzubiaga, C. (1991). Caffeine and theophylline as adenosine receptor antagonists in humans. Journal of Pharmacology and Experimental Therapeutics 258:588-593.

Brice, C. and Smith, A.P. (2002). Factors associated with caffeine consumption. International Journal of Food Sciences and Nutrition 53:55-64.

Cohen, S. and Booth, G.H. (1975). Gastric acid secretion and lower-esophagealsphincter pressure in response to coffee and caffeine. New England Journal of Medicine 293:897-899.

Doepker, C., Lieberman, H., Smith, A.P., Peck, J., El-Sohemy, A. and Welsh, B. (2016). Caffeine: Friend or Foe? Annual Review of Food Science and Technology 7:6.1-6.22.

Franchetti, P., Messini, L., Cappellacci, L., Grifantini, M., Lucacchini, A., Martini, C. and Senatore, G. (1994). 8-Azaxanthine derivatives as antagonists of adenosine receptors. Journal of Medical Chemistry 37:2970-2975.
Fredholm, B. (1995). Adenosine, adenosine receptors and the actions of caffeine. Pharmacology and Toxicology 76:93-101.

Fredholm, B.B., Battig, K., Holmen, J., Nehlig, A. and Zvartau, E.E. (1999). Actions of caffeine in the brain with special reference to factors that contribute to its widespread use. Pharmacological Reviews 51:83-133.

Garrett, B.E. and Griffiths, R.R. (1997). The role of dopamine in the behavioral effects of caffeine in animals and humans. Pharmacology Biochemistry $\backsim$ Behavior 57:533-541.

Gilbert, R.M. (1984). Caffeine consumption. In G.A. Spiller (Ed), The Methylxanthine beverages and Food: Chemistry, consumption and health effects. Springer: Berlin. pp. $185-213$.

Glade, M.J. (2010) Caffeine - Not just a stimulant. Nutrition 26:932-938.

Grosso, G., Micek, A., Castellano, S., Pajak, A. and Galvano, F. (2016). Coffee, tea, caffeine and the risk of depression: A systematic review and dose-response meta-analysis of observational studies. Molecular Nutrition and Food Research 60:223-234

James, J.E. (1990). The influence of user status and anxious disposition on the hypertensive effects of caffeine. International Journal of Psychophysiology 10:171-179.

Jarvis, M.J. (1993). Does caffeine intake enhance absolute levels of cognitive performance? Psychopharmacology 110:45-52.

Ker, K., Edwards, P.J., Felix, L.M., Blackhall, K. and Roberts, I. (2010). Caffeine for the prevention of injuries and errors in shift workers (Review). The Cochrane Collaboration. Chichester: Wiley.

Koot, P. and Deurenberg, P. (1995). Comparison of changes in energy expenditure and body temperatures after caffeine consumption. Annals of Nutrition and Metabolism 39:135-142.

Lane, J.D., Adcock, R.A., Williams, R.B. and Kuhn, C.M. (1990). Caffeine effects on cardiovascular and neuroendocrine responses to acute psychosocial stress and their relationship to level of habitual caffeine consumption. Psychosomatic Medicine 52:320-336.

Lara, D.R. (2010) Caffeine, mental health, and psychiatric disorders. Journal of Alzheimer's Disease 20:Suppl.1, S239-48.

Lieberman, H.R. (1992). Caffeine. In: Handbook of human performance, Vol.2: Health and performance. (eds) A.P. Smith and D.M. Jones. London: Academic Press. pp. 49-72.

Lieberman, H.R., Tharion, W.J., Shukitt-Hale, B. Speckman, K.L. and Tulley, R. (2002). Effects of caffeine, sleep loss, and stress on cognitive performance and mood during U.S. Navy SEAL training. Psychopharmacology 164:250-261. https://doi.org/10.1007/s00213-002-1217-9

Lovallo, W.R., Pincomb, G.A., Sung, B.H., Passey, R.B., Sausen, K.P. and Wilson, K.F. (1989). Caffeine may potentiate adrenocortical stress responses in hypertension-prone men. Hypertension 14:170-176.

Nehlig, A. (1994). Caffeine, brain energy metabolism and blood flow: A basis for the understanding of behavioral effects of the methylxanthines. Pharmacopsychoecologia 7:97-107.

Nehlig, A. (1999). Are we dependent upon coffee and caffeine? A review of human and animal data. Neuroscience and Biobehavioral Reviews 23:563-76.

Nehlig, A., Daval, J.L. and Debry, G. (1992). Caffeine and the central nervous system: mechanisms of action, biochemical, metabolic and psychostimulant effects. Brain Research Reviews 17:139-170.

Poehlman, E.T, LaChance, P., Tremblay, A., Nadeau, A., Dussault, J., Thériault, G., Després, J.P. and Bouchard, C. (1989). The effect of prior exercise and caffeine ingestion on metabolic rate and hormones in young adult males. Canadian Journal of Physiology and Pharmacology 67:10-6.

Rall, T.W. (1980). Central nervous stimulants. The Xanthines. In A. GoodmanGilman, L.S. Goodman and A. Gilman (Eds). The Pharmacological Basis of Therapeutics. MacMillan: New York. pp. 592-607.

Riedel, W., Hogervorst, E., Leboux, R. and Verhey, F. (1995). Caffeine attenuates scopolamine-induced memory impairment in humans. Psychopharmacology 122:158-168.

Roache, J.D. and Griffiths, R.R. (1987). Interactions of diazepam and caffeine: behavioral and subjective dose effects in humans. Pharmacology Biochemistry and Behavior 26:801-12.

Smith, A., Johal, S.S., Wadsworth, E., Davey Smith G. and Peters, T. (2000). The scale of occupational stress: the bristol stress and health at work study. HSE Books. Report 265/2000.

Smith, A.P. (2002). Effects of caffeine on human behaviour. Food and Chemical Toxicology 40:1243-1255. 
Smith, A.P. (2005a). Caffeine. In: Nutritional Neuroscience. Edited by H. Lieberman, R. Kanarek and C. Prasad, 335-359. London: Taylor \& Francis.

Smith, A.P. (2005b). Caffeine at work. Human Psychopharmacology: Clinical and Experimental 20:441-445.

Smith, A.P. (2009). Caffeine, cognitive failures and health in a non-working community sample. Human Psychopharmacology: Clinical and Experimental 24:29-34.

Smith, A.P. (2011). Caffeine: Practical implications. In: Diet, Brain, Behavior: Practical Implications. Eds: R.B. Kanarek and H.R. Lieberman. Taylor \& Francis. pp. 271-292.

Smith, A.P. (2014). Caffeine, Performance and Well-being. In: Chapter 6: Caffeine Effects on the Central Nervous System and Behavioral Effects Associated with Caffeine Consumption. In: Caffeine in Food and Dietary Supplements: Examining Safety: Workshop summary. Institute of Medicine: National Academy of Sciences, Washington. pp. 114-118.

Smith, A.P. (2018). The psychobiological processes underpinning the effects of caffeine. In: P. Murphy (ed), Routledge International Handbook of Psychobiology. London New York: Routledge. ISBN: 978-1-138-18800-6 (hbk) ISBN: 978-1-31564276-5 (ebk). pp 239-250.
Smith, A.P., Brice, C.F., Nash, J., Rich, N. and Nutt, D.J. (2003). Caffeine and central noradrenaline: effects on mood and cognitive performance. Journal of Psychopharmacology 17:283-292.

Smith, B.D., Davidson, R.A. and Green, R.L. (1993). Effects of caffeine and gender on physiology and performance: further tests of a biobehavioral model. Physiology and Behavior 54:415-22.

Smits, P., Temme, L. and Thien, T. (1993). The cardiovascular interaction between caffeine and nicotine in humans. Clinical Pharmacology \& Therapeutics 54:194-204.

Wadsworth, E.J.K., Simpson, S.A., Moss, S.C. and Smith, A.P. (2003). The bristol stress and health study: accidents, minor injuries and cognitive failures at work. Occupational Medicine 53:392-397.

Wang, L., Shen, X., Wu, Y. and Zhang, D. (2015). Coffee and caffeine consumption and depression: A meta-analysis of observational studies. Australia and New Zealand Journal of Psychiatry 50:228-242.

Wesnes, K.A., Barrett, M.L. and Udani, J.K. (2013). An evaluation of the cognitive and mood effects of an energy shot over a $6 \mathrm{~h}$ period in volunteers. A randomized, double-blind, placebo controlled, cross-over study. Appetite 67:105-113.

Zigmond, A.S. and Snaith, R.P. (1983). The hospital anxiety and depression scale. Acta Psychiatrica Scandinavica 67:361-370. 